\title{
Phase II study of radiotherapy and temsirolimus versus radiochemotherapy with temozolomide in patients with newly diagnosed glioblastoma without MGMT promoter hypermethylation (EORTC 26082)
}

Wick, Wolfgang ; Gorlia, Thierry ; Bady, Pierre ; Platten, Michael ; van den Bent, Martin J ; Taphoorn, Martin J B ; Steuve, Jonathan ; Brandes, Alba A ; Hamou, Marie-France ; Wick, Antje ; Kosch, Markus ; Weller, Michael ; Stupp, Roger ; Roth, Patrick ; Golfinopoulos, Vassilis ; Frenel, Jean-Sebastien ; Campone, Mario ; Ricard, Damien ; Marosi, Christine ; Villà, Salvador ; Weyerbrock, Astrid ; Hopkins, Kirsten ; Homicsko, Krisztian ; Lhermitte, Benoit ; Pesce, Gianfranco ; Hegi, Monika E

\begin{abstract}
PURPOSE: EORTC 26082 assessed the activity of temsirolimus in patients with newly diagnosed glioblastoma harboring an unmethylated O6 methlyguanine-DNA-methlytransferase (MGMT) promoter. PATIENTS AND METHODS: Patients $(n=257)$ fulfilling eligibility criteria underwent central MGMT testing. Patients with MGMT unmethylated glioblastoma $(n=111)$ were randomized 1:1 between standard chemo-radiotherapy with temozolomide or radiotherapy plus weekly temsirolimus (25 mg). Primary endpoint was overall survival at 12 months (OS12). A positive signal was considered $>38$ patients alive at 12 months in the per protocol population. A non-comparative reference arm of 54 patients evaluated the assumptions on OS12 in a standard-treated cohort of patients. Pre-specified post hoc analyses of markers reflecting target activation were performed. RESULTS: Both therapies were administered per protocol with a median of 13 cycles of maintenance temsirolimus. Median age was 55 and 58 years in the temsirolimus and standard arms, the WHO performance status 0 or 1 for most patients (95.5\%). In the per protocol population, 38 of 54 patients treated with temsirolimus reached OS12. The actuarial 1-year survival was $72.2 \%$ [95\% CI (58.2-82.2)] in the temozolomide arm and $69.6 \%$ [95\% CI (55.8-79.9) $]$ in the temsirolimus arm $[\mathrm{HR}=1.16,95 \% \mathrm{CI}(0.77-1.76), \mathrm{p}=0.47]$. In multivariable prognostic analyses of clinical and molecular factors phosphorylation of mTORSer2448 in tumor tissue $(\mathrm{HR}=0.13$, 95\% CI (0.04-0.47), $\mathrm{p}=0.002)$, detected in 37.6\%, was associated with benefit from temsirolimus. CONCLUSIONS: Temsirolimus was not superior to temozolomide in patients with an unmethylated MGMT promoter. Phosphorylation of mTORSer2448 in the pretreatment tumor tissue may define a subgroup benefitting from mTOR inhibition.
\end{abstract}

DOI: https://doi.org/10.1158/1078-0432.CCR-15-3153

Posted at the Zurich Open Repository and Archive, University of Zurich

ZORA URL: https://doi.org/10.5167/uzh-124235

Journal Article

Accepted Version

Originally published at:

Wick, Wolfgang; Gorlia, Thierry; Bady, Pierre; Platten, Michael; van den Bent, Martin J; Taphoorn, Martin J B; Steuve, Jonathan; Brandes, Alba A; Hamou, Marie-France; Wick, Antje; Kosch, Markus; 
Weller, Michael; Stupp, Roger; Roth, Patrick; Golfinopoulos, Vassilis; Frenel, Jean-Sebastien; Campone, Mario; Ricard, Damien; Marosi, Christine; Villà, Salvador; Weyerbrock, Astrid; Hopkins, Kirsten; Homicsko, Krisztian; Lhermitte, Benoit; Pesce, Gianfranco; Hegi, Monika E (2016). Phase II study of radiotherapy and temsirolimus versus radiochemotherapy with temozolomide in patients with newly diagnosed glioblastoma without MGMT promoter hypermethylation (EORTC 26082). Clinical Cancer Research, 22(19):4797-4806.

DOI: https://doi.org/10.1158/1078-0432.CCR-15-3153 
1 Phase II study of radiotherapy and temsirolimus versus radiochemotherapy

2 with temozolomide in patients with newly diagnosed glioblastoma without

3 MGMT promoter hypermethylation (EORTC 26082)

4

$5 \quad$ 1,2 Wolfgang Wick, ${ }^{3}$ Thierry Gorlia, ${ }^{4,5}$ Pierre Bady, ${ }^{1,6}$ Michael Platten, ${ }^{7}$ Martin J van den Bent,

$6{ }^{8}$ Martin JB Taphoorn, ${ }^{3}$ Jonathan Steuve, ${ }^{9}$ Alba A. Brandes, ${ }^{5,10}$ Marie-France Hamou, ${ }^{1}$ Antje

7 Wick, ${ }^{11}$ Markus Kosch, ${ }^{13}$ Michael Weller, ${ }^{10}$ Roger Stupp, ${ }^{13}$ Patrick Roth, ${ }^{3}$ Vassilis

8 Golfinopoulos, ${ }^{12}$ Jean-Sebastien Frenel, ${ }^{12}$ Mario Campone, ${ }^{14}$ Damien Ricard, ${ }^{15}$ Christine

9 Marosi, ${ }^{16}$ Salvador Villa, ${ }^{17}$ Astrid Weyerbrock, ${ }^{18}$ Kirsten Hopkins, ${ }^{19}$ Krisztian Homicsko,

$10 \quad{ }^{20}$ Benoit Lhermitte, ${ }^{21}$ Gianfranco Pesce, ${ }^{5,10}$ Monika E Hegi

$12{ }^{1}$ Neurology Clinic, University of Heidelberg and ${ }^{2}$ Clinical Cooperation Unit (CCU)

13 Neurooncology, German Cancer Consortium (DKTK), German Cancer Research Center

14 (DKFZ), Heidelberg, Germany; ${ }^{3}$ European Organisation for Research and Treatment of

15 Cancer (EORTC); ${ }^{4}$ SIB Swiss Institute of Bioinformatics, ${ }^{5}$ Neuroscience Research Center,

16 University Hospital Lausanne (CHUV), both Lausanne, Switzerland; ${ }^{6} \mathrm{CCU}$ Brain Tumor

17 Immunology, DKFZ, Heidelberg, Germany; 'Department of Neurology/Neuro-Oncology,

18 Erasmus MC - Cancer Institute, Rotterdam; ${ }^{8}$ Neuro-oncology Unit, MC Haaglanden, The

19 Hague, both The Netherlands; ${ }^{9}$ Department of Medical Oncology, Ospedale Bellaria,

20 Bologna, Italy; ${ }^{10}$ Department of Neurosurgery, CHUV, Lausanne, Switzerland; ${ }^{11}$ Pfizer,

21 Berlin, Germany; ${ }^{12} 1$-Institut de Cancérologie de I'OUEST, Saint Herblain-Nantes Cedex,

22 France; ${ }^{13}$ Department of Neurology, University Hospital and University of Zurich; ${ }^{14} \mathrm{AP}-\mathrm{HP}$,

23 Groupe Hospitalier Pitié-Salpêtrière, Service de Neurologie 2-Mazarin; UMR8257 MD4

24 Cognac G, CNRS, Service de Santé des Armées, Université Paris Descartes, Paris, France;

$25{ }^{15}$ General Hospital AKH, Medical University Vienna, Austria; ${ }^{16}$ Institut Catala d'Oncologia

26 (ICO). Hospital Germans Trias Pujol, Badalona, Barcelona, Spain; ${ }^{17}$ Department of

27 Neurosurgery, Medical Center - University of Freiburg, Germany; ${ }^{18}$ University Hospitals 
28 Bristol NHS Foundation Trust - Bristol Haematology and Oncology Centre, Bristol, U.K.;

$29{ }^{19}$ Department of Oncology, ${ }^{20}$ Institute of Pathology, both CHUV, Lausanne, Switzerland;

$30 \quad{ }^{21}$ Department of Radio-oncology, Oncology Institute of Southern Switzerland, Bellinzona; all 31 Switzerland.

33 Running Head: Temsirolimus for newly diagnosed glioblastoma

Keywords: mTOR, biomarker, randomized trial, EORTC, radiochemotherapy, MGMT

Funding: Pfizer provided an unrestricted academic grant. Swiss National Science

Foundation (FN31003A-138116 to M.E.H) supported the biomarker analyses.

Prior presentation: This report has been presented in part as abstract 2003 at ASCO 2014 by W. Wick.

Trial registration ID: NCT01019434

Address correspondence to: Wolfgang Wick, MD

University of Heidelberg

Tel.: $+49(0) 6221 / 56-7075$

Fax: $+49(0) 6221 / 56-7554$

Potential conflict of interest: M.W. has received honoraria from MSD and Merck Serono. research funding from MSD. M.W. has received research funding from Merck Serono and 
56 Novocure. W.W. has received research funding from Apogenix, Boehringer Ingelheim,

57 Genentech Roche and Pfizer. R.S. and M.W. have a consultant relationship with MSD and 58 Novocure. M.W. have a consultant relationship with Merck Serono. A.A.B., M.J.v.d.B., P.R., 59 R.S., M.J.B.T., M.W. and W.W. have a consultant relationship with Genentech/Roche. M.K. 60 is an employee of Pfizer, the manufacturer of Temsirolimus.

61 M.E.H. has served on advisory boards for MSD, Genentech/Roche, and MDxHealth, and 62 has provided services to Novocure.

63 T.G., P.B., M.P., J.S., M.-F.H., A.W., V.G., J.-S.F., M.C. and B.L. do not have any potential 64 conflicts of interest.

Word count 2996

Figures

4

Tables

1

Statement of clinical relevance: The prospective randomized EORTC 26082 trial assessed the tolerability and efficacy of the mechanistic target of rapamycin (mTOR) inhibitor temsirolimus in patients with newly diagnosed, 06 methlyguanine-DNAmethlytransferase (MGMT) promoter unmethylated glioblastoma. Temozolomide could be omitted without detriment in the experimental arm. Efficacy of radiotherapy plus temsirolimus failed to reach the pre-specified number of patients alive at 12 months. Prespecified assessment of activity in the mTOR pathway allows to suggest that one third of patients with phosphorylated mTOR at Ser2448 derive a robust and clinically relevant survival benefit and will be candidates for clinical development of temsirolimus as a targeted therapy in a molecularly defined subgroup. 
EORTC 26082

Wick et al.

Page 4

$2 / 26 / 2016$

83

84

85

86

87

88

89

90

\section{ABSTRACT}

Purpose: EORTC 26082 assessed the activity of temsirolimus in patients with newly diagnosed glioblastoma harboring an unmethylated 06 methlyguanine-DNAmethlytransferase (MGMT) promoter.

Patients and Methods: Patients $(n=257)$ fulfilling eligibility criteria underwent central MGMT testing. Patients with MGMT unmethylated glioblastoma $(n=111)$ were randomized $1: 1$ between standard chemo-radiotherapy with temozolomide or radiotherapy plus weekly temsirolimus (25 mg). Primary endpoint was overall survival at 12 months (OS12). A positive signal was considered $>38$ patients alive at 12 months in the per protocol population. A noncomparative reference arm of 54 patients evaluated the assumptions on OS12 in a standardtreated cohort of patients. Pre-specified post hoc analyses of markers reflecting target activation were performed.

Results: Both therapies were administered per protocol with a median of 13 cycles of maintenance temsirolimus. Median age was 55 and 58 years in the temsirolimus and standard arms, the WHO performance status 0 or 1 for most patients (95.5\%). In the per protocol population, 38 of 54 patients treated with temsirolimus reached OS12. The actuarial 1-year survival was $72.2 \%[95 \% \mathrm{Cl}(58.2-82.2)]$ in the temozolomide arm and $69.6 \%$ [95\% $\mathrm{Cl}(55.8-79.9)]$ in the temsirolimus arm $[\mathrm{HR}=1.16,95 \% \mathrm{Cl}(0.77-1.76), p=0.47]$. In multivariable prognostic analyses of clinical and molecular factors phosphorylation of mTORSer2448 in tumor tissue $(\mathrm{HR}=0.13,95 \% \mathrm{Cl}(0.04-0.47), \mathrm{p}=0.002)$, detected in $37.6 \%$, was associated with benefit from temsirolimus.

Conclusions: Temsirolimus was not superior to temozolomide in patients with an unmethylated MGMT promoter. Phosphorylation of mTORSer2448 in the pretreatment tumor tissue may define a subgroup benefitting from mTOR inhibition. 
EORTC 26082

Wick et al.

Page 5

$2 / 26 / 2016$

\section{INTRODUCTION}

112 The serine/threonine kinase, mechanistic target of rapamycin (mTOR) serves as a hub

113 integrating multiple intra- and extracellular cues in cancer cells (1). mTOR is involved in the

114 formation of two multi-protein complexes, mTORC1 and mTORC2, that direct cell

115 metabolism, growth, proliferation, survival, and angiogenesis.

116 Preclinical studies suggested an enhanced activity of mTOR inhibition in PTEN-deficient

117 tumour models $(2,3)$.

118 Activation of the PI3K/AKT/mTOR pathway has been associated with reduced survival of

119 glioma patients (4) and this signalling pathway has been subjected to a number of negative

120 single- or multi-targeted therapies including the mTOR inhibitor rapamycin or its derivatives,

121 the 'rapalogs' everolimus (RAD001), deforolimus (AP23573), and temsirolimus (CCI-779) (5-

$1229)$.

123 The experience with temozolomide (TMZ) teaches that limited activity at recurrence (10)

124 may still relevantly modify the disease in patients with newly diagnosed glioblastoma when 125 combined with radiotherapy (11). Accordingly, mTOR inhibition has been considered an 126 option for patients with treatment-naïve glioblastomas that likely lack some of the 127 mechanisms of resistance acquired at recurrence.

128 Temsirolimus $\left(\right.$ Torise $^{\circledR}$ ) has been approved for advanced renal cell carcinoma (12) and 129 relapsed or refractory mantle cell lymphoma (13). Additive effects of temsirolimus plus 130 radiotherapy (RT) in preclinical models demonstrate that temsirolimus could complement the 131 genotoxic activity of RT in the treatment of newly diagnosed glioblastoma. However, 132 combination of TMZ and temsirolimus plus RT was too toxic (14).

133 Therefore, the rationale of this study was to test the biological effects of mTOR inhibition 134 when combined with ionizing radiation in patients in whom TMZ could be safely omitted. To 135 this end patients with tumors with an unmethylated O6 methlyguanine-DNA136 methlytransferase (MGMT) gene promoter were selected for the trial, as they derive little if 137 any benefit from the addition of TMZ (15). Another aim was to identify biological factors, i.e. 
Author manuscripts have been peer reviewed and accepted for publication but have not yet been edited.

EORTC 26082

Wick et al.

Page 6

$2 / 26 / 2016$

138 biomarkers linked to benefit from mTOR inhibition. Temsirolimus may counteract therapy-

139 induced angiogenesis and invasion $(16,17)$.

140

Downloaded from clincancerres. aacrjournals.org on May 19, 2016. @ 2016 American Association for Cancer Research. 
EORTC 26082

Wick et al.

\section{PATIENTS AND METHODS}

\section{Clinical Trial}

\section{Study design and treatment}

145 Patients for EORTC 26082 (NCT01019434) were recruited at 14 study sites in 10 countries

146 in Europe. First, patients were registered after consenting for independent pathology review

147 and central testing of the MGMT promoter methylation status by licensed laboratories of

148 MDxHealth (Herstal, Belgium) using quantitative methylation-specific polymerase chain

149 reaction of DNA isolated from macro-dissected formalin fixed paraffin embedded tumor

150 sections (18). Patients were considered MGMT unmethylated, applying a safety margin,

151 when the ratio of MGMT to the control gene $A C T B$ was $<0 \cdot 6$, calculated as (methylated

$152 M G M T / A C T B) \times 1000$. This corresponds to the lower bound of the $95 \%$ confidence interval

153 established in a cohort of 602 glioblastoma samples screened in the CENTRIC trial where

154 the cut-off corresponding to the established nadir was at a ratio of 2 that separates

155 methylated from unmethylated. (19) as visualized in Supplementary Figure S1. A minimum

156 of 1,250 copies of $A C T B$ were required for a valid result, unless the copy number for

157 methylated MGMT was ten or more, which was scored as MGMT methylated.

158 Eligible patients (see Supplementary Information) were randomly assigned to receive 159 either standard chemoradiotherapy $(T M Z / R T \rightarrow T M Z)(11)$, or standard fractionated RT with 160 concomitant temsirolimus (standard dose of $25 \mathrm{mg}$ i.v. weekly beginning at day -7 from the 161 start of RT, to be continued until disease progression) (Figure 1 and Supplement). The 162 study was conducted according to the Declaration of Helsinki, the International Conference 163 on Harmonisation note for good clinical practice (Topic E6, 1996), and regulatory 164 requirements.

165 This study was funded by a grant from Pfizer, Berlin, Germany (details on the Role of the 166 Funding Source in the Supplement). 
169 Randomisation was performed centrally using an interactive voice response system.

170 Patients were stratified according to age, WHO performance status and baseline steroids.

171 As this was an open-label study, no blinding procedures were applied.

173 Study endpoints

174 The primary endpoint was overall survival at 12 months (OS12) to avoid issues around

175 pseudoprogression and generate a timely signal. Secondary endpoints included 176 progression-free survival (PFS), OS, safety and assessment of prognostic and predictive 177 biomarkers.

Outcome measures and statistical analyses

180 OS12 was defined as the fraction of patients alive at 12 months from randomisation; PFS

181 was defined as duration from randomisation until first observation of PD or death from any

182 cause or censored at last disease assessment without progression or start of second anti-

183 cancer therapy; OS was defined as time from randomisation until death or last visit.

184 PFS was assessed locally by investigators according to the Macdonald criteria (20), in case

185 of suspected pseudoprogression investigators were advised to continue treatment per

186 protocol and repeat imaging after 1-2 months. If progression was confirmed, the date of first

187 observation of tumor progress was used for the analyses.

188 Adverse events (AEs) were coded according to the Medical Dictionary for Regulatory

189 Activities version 15.0, and their severity was graded according to National Cancer Institute

190 Common Terminology Criteria for Adverse Events version 3.0.

191 A Fleming one-sample one-stage testing procedure was used in each arm. It was assumed 192 that with OS12 lower or equal to $60 \%(\mathrm{PO})$ the therapeutic activity of temsirolimus (CCl-779) 193 was too low(11). While a OS12 greater or equal to $80 \%$ (P1) implied that the therapeutic 194 activity of temsirolimus (CCl-779) was adequate Type I ( $\alpha$ ) and II ( $\beta$ ) errors were both equal 195 to $5 \%$. Under these hypotheses, a sample size of 54 eligible patients in each arm was 
196 required. The decision rule was that if $>38$ eligible patients were alive at 1 year, it was

197 concluded that the therapeutic activity of temsirolimus was adequate.

198 All statistical analyses were performed on mature data (median follow-up 32 months) by

199 Thierry Gorlia. The concept of a non-comparative control arm allows for adjustment of the 200 initial assumptions based on contemporary control treatment. The trial would be insufficient

201 to confirmatory declare efficacy. However, statistical comparisons are still valid and useful

202 for hypothesis-generation and exploratory analyses.

203 The OS12 was also computed in the TMZ/RT $\rightarrow$ TMZ arm in order to assess the consistency 204 with P0.

\section{Biomarker substudy}

207 Tissue Micro Array, Immunohistochemistry and FISH EGFR

208 Tissue micro arrays (TMA) were constructed using recipient paraffin blocks with an agarose 209 matrix (21). Immunohistochemical analyses and Fluorescent In Situ Hybridization (FISH) 210 were performed in duplicate on sections from 2 replicate TMAs basically as recommended

211 by the manufacturers (see supplemental methods for antibody description, conditions and

212 dilutions; FISH probes). Markers for post hoc analyzes of the mTOR pathway were pre213 specified in the protocol (phosphorylated S6 ribosomal protein, p-S6RP ${ }^{\text {Ser235/236; }}$

214 phosphorylated AKT, p-AKT ${ }^{\text {Ser473; }}$ PTEN; phosphorylated AKT1 Substrate 1 (proline-rich),

215 p-PRAS40 ${ }^{\text {Thr246 }}$; phosphorylated extracellular signal-regulated linase, ERK1/2 ${ }^{\text {Thr202/Tyr204 }}$ ) or

216 based on a more recent study (phosphorylated p-mTOR $\left.{ }^{\text {Ser2448 }}\right)(22,23)$. Scoring and

217 definition of dichotomization is detailed in the Supplemental Methods.

219 Multidimensional marker analysis

220 The centered score table of the markers containing missing values was analysed by 221 principal component analysis. Non-linear Iterative Partial Least Squares (NIPALS) algorithm 222 (24) was used to perform singular-value decomposition with missing value and to complete 
223 the data. A consensus hierarchical clustering analysis (25) based on Euclidean distance and

224 Ward's algorithm was used to investigate the optimal number of clusters. The association

225 among marker scores was illustrated by network representation based on Spearman

226 correlation. Analyses and graphical representations were performed using R-3.2.0 and the R

227 packages mixOmics, qgraphs (26) and ConsensusClusterPlus.

229 Statistical analysis

230 The scores of the P-markers were dichotomized into negative (scores 0,1 , corresponding to

2310 to $10 \%$ ) vs positive (scores 2 to $5,>10 \%$ ). Study stratification factors (age, WHO

232 performance status, baseline steroids) and molecular markers were correlated to OS.

233 Treatment arms were compared with a log-rank test at $5 \%$ significance. For each of them,

234 PFS and OS were estimated using the Kaplan-Meier (KM) method. Associations of marker

235 profiles with treatment efficacy were presented by Forest Plot and significance was

236 assessed with the test for interaction computed from a Cox model including the treatment,

237 the marker and their interaction term. A 5\% significance was used for screening predictive

238 markers. For each factor, univariable survival estimates were calculated using the KM

239 technique in the TMZ and temsirolimus arms. Hazard Ratios obtained from univariable Cox

240 models were presented with $95 \%$ Confidence Intervals $(\mathrm{Cl})$ (details in the Supplement). 
EORTC 26082

Wick et al.

Page 11

$2 / 26 / 2016$

\section{RESULTS}

244 Patients

245 Overall, 257 patients were registered, screened for eligibility and assessed for MGMT 246 promoter methylation status, whereof 28 patients were registered after screening through the 247 CENTRIC trial that selected MGMT methylated patients only (19); 190 patients were found 248 to have glioblastoma with an unmethylated MGMT promoter applying the cut-off with a 249 safety margin (Figure S1). The primary reasons for initially registered patients not to 250 continue to randomisation were hypermethylated MGMT status $(n=67)$, withdrawal of 251 consent $(n=24)$, and other reasons $(n=55)$, including insufficient tumor material $(n=30)$, and 252 AEs after surgery ( $n=8)$ (Figure 1). A total of 111 patients were randomised from December 2532009 through September 2012 and constituted the ITT population: 56 patients were

254 scheduled to receive weekly temsirolimus in addition to standard RT (temsirolimus arm) and 25555 were to receive $\mathrm{TMZ} / \mathrm{RT} \rightarrow \mathrm{TMZ}$ alone (control arm). In the safety population, i.e. patients 256 with at least one dose of drug, there were 53 patients in the temsirolimus and 51 patients in 257 the TMZ arm.

258 Median follow-up was $33(95 \% \mathrm{Cl}: 23-37)$ months in the temsirolimus and 32 (95\% Cl: 22-

259 40) months in the TMZ arm. The median duration from operation to randomisation was 2.6 260 weeks (range 0.4-6.1 weeks). Patient baseline and demographic characteristics were well 261 balanced between treatment arms except for the WHO Performance status between PSO 262 and PS1, which favored the control arm. This is explained since the stratification was PS 0-1 vs PS2 (Table 1).

264 In the biomarker cohort $(n=88)$, only one patient sample displayed positive staining for the

265 IDH1-R132H mutant (1/78; 1.3\%), an expected low frequency, since $75 \%$ of the few IDH1 266 mutant glioblastoma are MGMT hypermethylated (27). The frequency of EGFR amplification 267 was in the expected range $(54 \%, 44 / 82)$. There was no difference in baseline characteristics 268 and outcome in patients with vs without markers assessment (Supplementary Figure S2, 
EORTC 26082

Wick et al.

Page 12

$2 / 26 / 2016$

Supplementary Table S1).

\section{Efficacy outcomes}

272 The median duration of radiotherapy was 6.1 weeks in both arms. Main reason for interrupting RT was technical or administrative (28\%). In median, RT was interrupted 2 days.

274 RT was completed by $>90 \%$ of patients. Concomitant treatment was delivered as planned

275 per protocol by $>90 \%$ of patients in both arms. Patients in the temsirolimus arm received the 276 drug for a median $(95 \% \mathrm{Cl})$ of 16 weeks post RT $(4.0-84.3)$, with a mean dose intensity of $27721.4(6.3-25) \mathrm{mg} /$ week.

278 Maintenance temsirolimus was administered per protocol at a median of 13 weekly cycles. 279 Median relative dose-intensity was $85.6 \%$. Twelve patients had a reduction in dose intensity 280 below $70 \%$, because of dose reduction (19.1\%: $6.4 \%$ for hematological toxicity, $10.6 \%$ for $281 \mathrm{AE}, 2.1 \%$ for other reasons), dose not given during at least one cycle $(68 \%$ : $6.3 \%$ for 282 hematological toxicity, $34 \%$ for non-hematological toxicity, $58 \%$ for other reasons) or 283 treatment delay (58\%: $2.1 \%$ for hematological toxicity, $17 \%$ for non-hematological toxicity, $28443 \%$ for other reasons).

285 Median OS was 14.8 (13.3-16.4) months in the temsirolimus arm and $16.0(13.8-18.2)$ in the 286 control arm (90 deaths; HR, 1.2; 95\% Cl, 0.8-1.8; $\mathrm{p}=0.47$; Figure 2A). The OS12 and OS24 287 rates did not differ between arms $(70 \%, 72 \%$ and $15 \%, 16 \%$, respectively). Median PFS as 288 assessed by the investigator was $5.4(95 \% \mathrm{Cl}, 3.7-6.1)$ months in the temsirolimus arm and $2896.0(95 \% \mathrm{Cl}, 2.8-8.0)$ months in the control arm (54 PFS events; HR, 1.26; $95 \% \mathrm{Cl}, 0.86-$ 290 1.86; $p=0.24 ;$ Figure 2B). In the per protoco/ population (see Supplementary Information),

29138 patients treated with temsirolimus had survived $\geq$ to 1 year. At least 39 patients were 292 needed to reach the targeted drug activity.

295 In the temsirolimus arm severe hematological toxicity was: neutropenia (G3: $n=1,1.9 \%$ ) and 296 Iymphocytopenia (G3: $n=9,16.4 \%, G 4: n=1,1.8 \%$ ). In the TMZ arm severe hematological 
EORTC 26082

Wick et al.

Page 13

$2 / 26 / 2016$

297 toxicity was: leukopenia G3 ( $n=2,3.8 \%)$, neutropenia G4 ( $n=2,3.8 \%)$, lymphocytopenia (G3:

$298 \mathrm{n}=14,26.4 \%, \mathrm{G} 4: \mathrm{n}=2,3.8 \%$ ) and thrombocytopenia (G3: $n=1,1.9 \%, \mathrm{G} 4: \mathrm{n}=1,1.9 \%$ ). There

299 was no other severe (G3/4) treatment-related AE with an incidence $>5 \%$ in either arm.

300

301 Molecular correlations with outcome

302 Markers interrogated for their relevance of targeting the mTOR signaling pathway $(22,23)$

303 are visualized in the mTOR KEGG pathway (28) (Supplementary Figure S3).

304 Phosphorylated $\mathrm{mTOR}^{\text {Ser2448 }}$ was associated with prolonged OS as evidenced by the

305 significant interaction term between treatment and $p-m T O R^{\operatorname{Ser} 2448}(p=0.047$, Figure 3$)$.

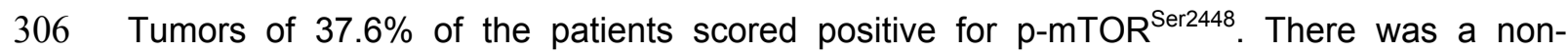

307 significant trend for longer OS when $\mathrm{p}-\mathrm{mTOR}^{\mathrm{Ser2448}}$ positive patients received temsirolimus

308 as compared with controls $(\mathrm{HR}=0.62,95 \% \mathrm{Cl} 0.26-1 \cdot 47, \mathrm{p}=0.27)$. When non-phosphorylated

$309 \mathrm{mTOR}^{\text {Ser2448 }}$ patients received temsirolimus a non-significant decrease in survival was

310 observed compared with controls $(\mathrm{HR}=1.77,95 \% \mathrm{Cl} 0.95-3.29, \mathrm{p}=0.07)$ (Figure 3). The

311 median $\mathrm{OS}$ in the temsirolimus group was 17.8 months $(\mathrm{Cl}, 14.1-28.0)$ for patients with $\mathrm{p}$ -

$312 \mathrm{mTOR}^{\mathrm{Ser} 2448}$ positive tumors and 13.1 months $(\mathrm{Cl}, 9.7-15.1)$ in the negative subgroup

$313(p=0.007$, Figure $3 A)$. In the $R T / T M Z \rightarrow T M Z$ control arm the median OS in the $p-m T O R^{\text {Ser2448 }}$

314 positive group was 14.0 months $(\mathrm{Cl}, 9.6-19.6)$ and 16.5 months $(\mathrm{Cl}, 9.5-18.8)$ in the p-

315 mTOR $^{\text {Ser2448 }}$ negative subgroup $(p=0.999)$. For $p-P R A S 40^{\text {Thr246, }}$, the interaction test with

316 treatment was borderline non-significant $(p=0.07)$. The impact of all other markers on

317 survival is illustrated in a forest plot for all other markers in Supplementary Figure S4.

318

319 A multi dimensional analysis used the full range of the scores of the mTOR-associated

320 markers integrated information for the identification of clinically relevant molecular subgroups

321 and to gain further insights on pathway interactions (Figure 4). The two first axes obtained

322 by PCA explained $57 \cdot 8 \%$ of the total inertia. The first axis was mainly explained by $p$ -

$323 \mathrm{mTOR}^{\mathrm{Ser} 2448}$ and p-PRAS40 ${ }^{\text {Thr246 }}$. The p-S6RP ${ }^{\text {Ser235/236 }}$ mainly contributed to the construction

324 of the second axis (Figures 4E and F). PTEN expression played a minor role in the 
325 structure of the score table (Figure 4F). Subgroups were determined by consensus 326 clustering. We kept the cluster based on two groups $(\mathrm{k}=2)$ by default, as no strong indication

327 for the optimal number of clusters was obtained and the sample size is limited

328 (Supplementary Figure S5). Cluster 2, highly enriched for p-mTOR ${ }^{\text {Ser2448 }}$-positive cases, 329 revealed a strong association with outcome in the temsirolimus treatment group and no 330 difference in the TMZ/RT $\rightarrow T M Z$ group (Figure 4). Significant interaction was observed with 331 treatment $(p=0.009)$ : in Cluster 2 the $\mathrm{HR}$ was $0.42(95 \% \mathrm{Cl} 0.15-1.13, p=0.08)$ and in Cluster

$3321 \mathrm{HR}=1.77(95 \% \mathrm{Cl} 0.96-3.25, \mathrm{p}=0.06)$.

333 In multivariable prognostic analyses of clinical and molecular factors (Supplementary Table

334 S1), p-mTOR ${ }^{\text {Ser2448 }}(\mathrm{HR}=0.13,95 \% \mathrm{Cl} 0.04-0.47, \mathrm{p}=0.002), \mathrm{p}-\mathrm{PRAS} 40^{\mathrm{Thr} 246}(\mathrm{HR}=0.50,95 \%$

$335 \mathrm{Cl} 0.21-1.18, \mathrm{p}=0.12), \mathrm{p}-\mathrm{ERK}^{\mathrm{Thr202/Tyr204}}(\mathrm{HR}=2.81,95 \% \mathrm{Cl}$ 0.97-8.09, $\mathrm{p}=0.06)$, but no clinical

336 factor was associated with OS in the temsirolimus arm. The PEV was equal to $14.9 \%$ In the

$337 \mathrm{TMZ}$ arm, there was a trend for decreased survival in $\mathrm{p}-\mathrm{AKT}^{\mathrm{Ser} 473}$ positive patients $(\mathrm{HR}=3.21$,

$33895 \% \mathrm{Cl} 0.89-11.56, \mathrm{p}=0.07, \mathrm{PEV}=4.5 \%$ ). None of the models had a PEV larger than $20 \%$. 
EORTC 26082

Wick et al.

Page 15

$2 / 26 / 2016$

\section{DISCUSSION}

342 This randomized, open label phase II trial investigating the mTOR inhibitor temsirolimus in

343 combination with RT for patients with low probability of benefit from the TMZ-based

344 radiochemotherapy failed to demonstrate the targeted outcome. Neither PFS nor OS

345 demonstrated a signal of relevant activity in the total trial population (Figure 2). Safety and

346 tolerability of temsirolimus in combination with standard RT were non-concerning and the

347 trial is an example that temozolomide can be safely omitted in patients with MGMT

348 unmethylated glioblastoma. The trial proposes $\mathrm{mTOR}^{\mathrm{Ser} 2448}$ phosphorylation as a biomarker

349 for benefit from mTOR inhibition. These results need further confirmation, and a trial to

350 prospectively assess the relevance of this putative biomarker is underway (NCT Neuro

351 Master Match, EudraCT 2015-002752-27).

352 The good outcome data in both arms of the trial prompted a comparison with the

353 EORTC26981-22981/NCIC CE3 trial. The comparison with our pivotal TMZ/RT $\rightarrow$ TMZ vs RT

354 trial (EORTC26981-22981/NCIC CE3) (29) was favourable in all aspects supporting the

355 principal rational to design trials for patients with MGMT unmethylated glioblastoma and

356 withhold TMZ in the experimental arm (Supplementary Results). Biases in favor of EORTC

35726082 may have been patient selection, and the lower number of patients on steroids (30).

358 Bevacizumab was administered in about $45 \%$ of the patients in both arms of EORTC 26082.

359 The OS of the EORTC 26082 arms is comparable to the outcome in the control arms of trials

360 with selection of MGMT unmethylated patients, with 13.4 months in the CORE trial $(95 \% \mathrm{Cl}$

361 12.2-14.3) with a bevacizumab use at recurrence of $22 \%(31)$ and 17.3 months $(95 \% \mathrm{Cl} 14.8-$

36220.4 months) in the GLARIUS trial with cross over to bevacizumab of $60 \%(32)$.

363 The EORTC 26082 trial aimed at not withholding TMZ from any patient with an equivocally

364 methylated MGMT promoter by applying a MGMT cut-off with a safety margin. This 365 prompted an adaption also in the GLARIUS trial (32) with similar design and therefore 366 demarcates an evolution from the S039 trial with enzastaurin (33). Two randomized phase III 367 trials in elderly patients with newly diagnosed glioblastoma further support a strictly 
368 predictive effect of the MGMT status for benefit from $\operatorname{TMZ}(34,35)$. However, we cannot 369 completely exclude a small baseline effect of TMZ despite the MGMT unmethylated state

370 (11). Hence, withholding TMZ outside trials and elderly patients with unmethlylated MGMT 371 promoter is not advocated by the present data. In the temsirolimus arm $59 \%(n=33)$ of the 372 patients received TMZ after treatment discontinuation, and $26 \%$ of TMZ patients $(n=14)$ were 373 re-challenged with $T M Z$, not being aware of the recent data from the DIRECTOR trial that re374 challenge with TMZ might be relevant only for patients with a methylated MGMT promoter 375 (36).

376 The choice of temsirolimus for patients with unmethylated glioblastoma was based on 377 preclinical data already highlighting that not every tumor responds to the treatment (37) as 378 well as a response may be only transient because of the overt feedback resistance 379 mechanisms (22, 38).

380 Molecular analyses of prespecified principal components of the EGFR-PI3-K/mTOR/AKT 381 pathway were performed. EORTC 26082 provides first evidence that $p-m_{T O R}{ }^{\text {er2 } 2448}$ and - to 382 a lesser extent - p-PRAS40 ${ }^{\text {Thr246 }}$ may serve as decisive biomarkers for the treatment of patients with newly diagnosed glioblastoma with an unmethylated MGMT promoter.

384 Phosphorylation of $\mathrm{mTOR}^{\mathrm{Ser} 2448}$ has been shown to be targeted and blocked by rapamycin, a 385 major metabolite of temsirolimus (39), while phosphorylated PRAS40 ${ }^{\text {Thr246 }}$ (substrate of 386 AKT1) relieves inhibitory function on mTORC1 (40). The survival curves may even suggest 387 that there is a detrimental effect of temsirolimus in p-mTOR ${ }^{\text {Ser2448 }}$ negative tumors (Figures 3 and 4). Previous trials testing temsirolimus at recurrence had focused on the PTEN status 389 with a PTEN deficiency as a prerequisite for response (22) or on other downstream mTOR

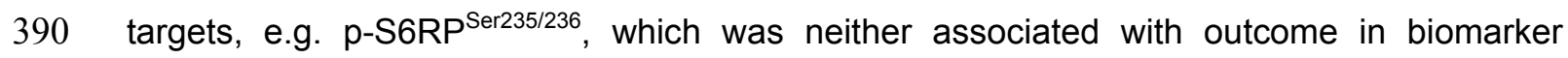
391 analyses of patients with recurrent glioblastoma receiving temsirolimus $(6,38)$ nor in this 392 study. It cannot be excluded that glioblastomas treated at recurrence may have changed mTOR pathway activity as compared to tumor specimen used for marker analyses obtained

394 at the first resection (41). Also, "paradoxical" activation of AKT by elimination of negative 395 feedback downregulating survival signaling has been postulated as potential resistance 
396 mechanism to mTOR inhibition in previous trials, based on the analyzes of paired tumor

397 specimen taken before and after treatment $(22,38)$. Interestingly, trials in other diseases did

398 not provide predictive biomarkers $(12,13)$.

399 The limitations of EORTC 26082 are the relatively small sample size of this non-comparative 400 phase II trial. For the biomarker analyses using IHC only a limited number of tumor tissue 401 samples from the ITT cohort were available. The findings should be validated by evaluation 402 of previous trials in particular in those treating newly diagnosed glioblastoma patients (42) 403 and the randomized phase II study RTOG-0913. Ongoing trials using mTOR inhibitors may 404 need to take into account a potentially detrimental effect in patients with an 405 unphosphorylated $\mathrm{mTOR}^{\mathrm{Ser2448}}$. Given the ongoing efforts of biomarker-driven basket trials 406 for patients with newly diagnosed glioblastoma, the concept of mTOR inhibition using the 407 marker predictive in this study, $\mathrm{p}-\mathrm{mTOR}^{\mathrm{Ser} 2448}$ is incorporated into the design of a future 408 study. 
EORTC 26082

Wick et al.

Page 18

$2 / 26 / 2016$

\section{REFERENCES}

412

413 1. Brennan CW, Verhaak RG, McKenna A, Campos B, Noushmehr H, Salama SR, et

414 al. The somatic genomic landscape of glioblastoma. Cell 2013;155: 462-77.

415 2. Neshat MS, Mellinghoff IK, Tran C, Stiles B, Thomas G, Petersen R, et al. Enhanced 416 sensitivity of PTEN-deficient tumors to inhibition of FRAP/mTOR. Proc Natl Acad Sci U S A $417 \quad$ 2001;98: 10314-9.

418 3. Podsypanina K, Lee RT, Politis C, Hennessy I, Crane A, Puc J, et al. An inhibitor of 419 mTOR reduces neoplasia and normalizes p70/S6 kinase activity in Pten+/- mice. Proc Natl $420 \quad$ Acad Sci U S A 2001;98: 10320-5.

421 4. Chakravarti A, Zhai G, Suzuki Y, Sarkesh S, Black PM, Muzikansky A, et al. The 422 prognostic significance of phosphatidylinositol 3-kinase pathway activation in human 423 gliomas. J Clin Oncol 2004;22: 1926-33.

424 5. Faivre S, Kroemer G, Raymond E. Current development of mTOR inhibitors as 425 anticancer agents. Nat Rev Drug Discov 2006;5: 671-88.

426 6. Galanis E, Buckner JC, Maurer MJ, Kreisberg JI, Ballman K, Boni J, et al. Phase II 427 trial of temsirolimus (CCl-779) in recurrent glioblastoma multiforme: a North Central Cancer 428 Treatment Group Study. J Clin Oncol 2005;23: 5294-304.

429 7. Doherty L, Gigas DC, Kesari S, Drappatz J, Kim R, Zimmerman J, et al. Pilot study of 430 the combination of EGFR and mTOR inhibitors in recurrent malignant gliomas. Neurology $431 \quad 2006 ; 67: 156-8$.

432 8. Kreisl TN, Lassman AB, Mischel PS, Rosen N, Scher HI, Teruya-Feldstein J, et al. A 433 pilot study of everolimus and gefitinib in the treatment of recurrent glioblastoma (GBM). J 434 Neurooncol 2009;92: 99-105.

435 9. Reardon DA, Desjardins A, Vredenburgh JJ, Gururangan S, Friedman AH, Herndon $436 \mathrm{JE}, 2 \mathrm{nd}$, et al. Phase 2 trial of erlotinib plus sirolimus in adults with recurrent glioblastoma. J 437 Neurooncol 2010;96: 219-30. 
438 10. Yung WK, Albright RE, Olson J, Fredericks R, Fink K, Prados MD, et al. A phase II

439 study of temozolomide vs. procarbazine in patients with glioblastoma multiforme at first 440 relapse. Br J Cancer 2000;83: 588-93.

441 11. Stupp R, Mason WP, van den Bent MJ, Weller M, Fisher B, Taphoorn MJB, et al.

442 Radiotherapy plus concomitant and adjuvant temozolomide for glioblastoma. N Engl J Med $443 \quad 2005 ; 352:$ 987-96.

444 12. Motzer RJ, Hudes GR, Curti BD, McDermott DF, Escudier BJ, Negrier S, et al. Phase $445 \mathrm{I} / \mathrm{II}$ trial of temsirolimus combined with interferon alfa for advanced renal cell carcinoma. J 446 Clin Oncol 2007;25: 3958-64.

447 13. Hess G, Herbrecht R, Romaguera J, Verhoef G, Crump M, Gisselbrecht C, et al. 448 Phase III study to evaluate temsirolimus compared with investigator's choice therapy for the 449 treatment of relapsed or refractory mantle cell lymphoma. J Clin Oncol 2009;27: 3822-9.

450 14. Sarkaria JN, Galanis E, Wu W, Dietz AB, Kaufmann TJ, Gustafson MP, et al. 451 Combination of temsirolimus (CCl-779) with chemoradiation in newly diagnosed 452 glioblastoma multiforme (GBM) (NCCTG trial N027D) is associated with increased infectious 453 risks. Clin Cancer Res 2010;16: 5573-80.

454 15. Hegi ME, Diserens AC, Gorlia T, Hamou MF, de Tribolet N, Weller M, et al. MGMT 455 gene silencing and benefit from temozolomide in glioblastoma. N Engl J Med 2005;352: 9974561003.

457 16. Abdollahi A, Lipson KE, Han X, Krempien R, Trinh T, Weber KJ, et al. SU5416 and 458 SU6668 attenuate the angiogenic effects of radiation-induced tumor cell growth factor 459 production and amplify the direct anti-endothelial action of radiation in vitro. Cancer Res 460 2003;63: 3755-63.

461 17. Wild-Bode C, Weller M, Rimner A, Dichgans J, Wick W. Sublethal irradiation 462 promotes migration and invasiveness of glioma cells: implications for radiotherapy of human 463 glioblastoma. Cancer Res 2001;61: 2744-50. 
464 18. Vlassenbroeck I, Califice S, Diserens AC, Migliavacca E, Straub J, Di Stefano I, et al.

465 Validation of real-time methylation-specific PCR to determine O6-methylguanine-DNA 466 methyltransferase gene promoter methylation in glioma. J Mol Diagn 2008;10: 332-7.

467 19. Stupp R, Hegi ME, Gorlia T, Erridge SC, Perry J, Hong YK, et al. Cilengitide 468 combined with standard treatment for patients with newly diagnosed glioblastoma with 469 methylated MGMT promoter (CENTRIC EORTC 26071-22072 study): a multicentre, 470 randomised, open-label, phase 3 trial. Lancet Oncol 2014;15: 1100-8.

471 20. Macdonald DR, Cascino TL, Schold SC, Jr., Cairncross JG. Response criteria for 472 phase II studies of supratentorial malignant glioma. J Clin Oncol 1990;8: 1277-80.

473 21. Yan P, Seelentag W, Bachmann A, Bosman FT. An agarose matrix facilitates 474 sectioning of tissue microarray blocks. J Histochem Cytochem 2007;55: 21-4.

475 22. Cloughesy TF, Yoshimoto K, Nghiemphu P, Brown K, Dang J, Zhu S, et al. Antitumor 476 activity of rapamycin in a Phase I trial for patients with recurrent PTEN-deficient 477 glioblastoma. PLoS Med 2008;5: e8.

478 23. Hegi ME, Diserens AC, Bady P, Kamoshima Y, Kouwenhoven MC, Delorenzi M, et 479 al. Pathway analysis of glioblastoma tissue after preoperative treatment with the EGFR 480 tyrosine kinase inhibitor gefitinib - A phase II trial. Mol Cancer Ther 2011;10: 1102-12.

481 24. Wold $\mathrm{H}$. Estimation of principal components and related models by iterative least 482 squares. Multivariate Analysis: Academic Press; 1966. p. 391-420.

483 25. Monti S, Tamayo P, Mesirov J, Golub T. Consensus clustering: A resampling-based 484 method for class discovery and visualization of gene expression microarray data. Machine 485 Learning 2003;52: 91-118.

486 26. Epskamp S, Cramer AOJ, Waldorp LJ, Schmittmann VD, Borsboom D. qgraph: 487 Network visualizations of relationships in psychometric data. J Stat Soft 2012;48: 1-18.

488 27. Bady P, Sciuscio D, Diserens AC, Bloch J, van den Bent MJ, Marosi C, et al. MGMT 489 methylation analysis of glioblastoma on the Infinium methylation BeadChip identifies two 490 distinct $\mathrm{CpG}$ regions associated with gene silencing and outcome, yielding a prediction 
491 model for comparisons across datasets, tumor grades, and CIMP-status. Acta Neuropathol $492 \quad 2012 ; 124: 547-60$.

493 28. Luo W, Brouwer C. Pathview: an R/Bioconductor package for pathway-based data 494 integration and visualization. Bioinformatics 2013;29: 1830-1.

495 29. Stupp R, Hegi ME, Mason WP, van den Bent MJ, Taphoorn MJ, Janzer RC, et al.

496 Effects of radiotherapy with concomitant and adjuvant temozolomide versus radiotherapy 497 alone on survival in glioblastoma in a randomised phase III study: 5-year analysis of the 498 EORTC-NCIC trial. Lancet Oncol 2009;10: 459-66.

499 30. Taal W, Oosterkamp HM, Walenkamp AM, Dubbink HJ, Beerepoot LV, Hanse MC, et

500 al. Single-agent bevacizumab or lomustine versus a combination of bevacizumab plus 501 lomustine in patients with recurrent glioblastoma (BELOB trial): a randomised controlled 502 phase 2 trial. Lancet Oncol 2014;15: 943-53.

503 31. Nabors LB, Fink KL, Mikkelsen T, Grujicic D, Tarnawski R, Nam DH, et al. Two 504 cilengitide regimens in combination with standard treatment for patients with newly 505 diagnosed glioblastoma and unmethylated MGMT gene promoter: results of the open-label, 506 controlled, randomized phase II CORE study. Neuro Oncol 2015;17: 708-17.

507 32. Herrlinger U, Schäfer N, Steinbach JP, Weyerbrock A, Hau P, Goldbrunner R, et al.

508 The randomized, multicenter glarius trial investigating bevacizumab/irinotecan vs standard 509 temozolomide in newly diagnosed, mgmt-non-methylated glioblastoma patients: final survival 510 results and quality of life. Neuro-Oncology 2014;16: ii23-ii4.

511 33. Wick W, Steinbach JP, Platten M, Hartmann C, Wenz F, von Deimling A, et al.

512 Enzastaurin before and concomitant with radiation therapy, followed by enzastaurin 513 maintenance therapy, in patients with newly diagnosed glioblastoma without MGMT 514 promoter hypermethylation. Neuro Oncol 2013;15: 1405-12.

515 34. Wick W, Platten M, Meisner C, Felsberg J, Tabatabai G, Simon M, et al. 516 Temozolomide chemotherapy alone versus radiotherapy alone for malignant astrocytoma in 517 the elderly: the NOA-08 randomised, phase 3 trial. Lancet Oncol 2012;13: 707-15. 
518 35. Malmstrom A, Gronberg BH, Marosi C, Stupp R, Frappaz D, Schultz H, et al.

519 Temozolomide versus standard 6-week radiotherapy versus hypofractionated radiotherapy

520 in patients older than 60 years with glioblastoma: the Nordic randomised, phase 3 trial.

521 Lancet Oncol 2012;13: 916-26.

522 36. Weller M, Tabatabai G, Kastner B, Felsberg J, Steinbach JP, Wick A, et al. MGMT

523 promoter methylation is a strong prognostic biomarker for benefit from dose-intensified

524 temozolomide rechallenge in progressive glioblastoma: The DIRECTOR trial. Clin Cancer 525 Res 2015;21: 2057-64.

526 37. Weiler M, Pfenning PN, Thiepold AL, Blaes J, Jestaedt L, Gronych J, et al. 527 Suppression of proinvasive RGS4 by mTOR inhibition optimizes glioma treatment. 528 Oncogene 2013;32: 1099-109.

529 38. Wen PY, Chang SM, Lamborn KR, Kuhn JG, Norden AD, Cloughesy TF, et al. Phase $530 \mathrm{I} / \mathrm{II}$ study of erlotinib and temsirolimus for patients with recurrent malignant gliomas: North 531 American Brain Tumor Consortium trial 04-02. Neuro Oncol 2014;16: 567-78.

532 39. Chiang GG, Abraham RT. Phosphorylation of mammalian target of rapamycin 533 (mTOR) at Ser-2448 is mediated by p70S6 kinase. J Biol Chem 2005;280: 25485-90.

534 40. Wiza C, Nascimento EB, Ouwens DM. Role of PRAS40 in Akt and mTOR signaling 535 in health and disease. Am J Physiol Endocrinol Metab 2012;302: E1453-60.

536 41. Kim H, Zheng S, Amini SS, Virk SM, Mikkelsen T, Brat DJ, et al. Whole-genome and 537 multisector exome sequencing of primary and post-treatment glioblastoma reveals patterns 538 of tumor evolution. Genome Res 2015;3: 114.

539 42. Ma DJ, Galanis E, Anderson SK, Schiff D, Kaufmann TJ, Peller PJ, et al. A phase II 540 trial of everolimus, temozolomide, and radiotherapy in patients with newly diagnosed 541 glioblastoma: NCCTG N057K. Neuro Oncol 2015;17: 1261-9. 
EORTC 26082

Wick et al.

Page 23

$2 / 26 / 2016$

545

546

547

548

550

551

552

553

554

555

556

557

558

559

560 The biomarker data were generated and evaluated by P.B., M.-F.H, B.L. and M.E.H.

561 Reference pathology was performed by B.L.

562 The statistical analyses were performed by T.G. and P.B.

563 The article was written by W.W. and M.E.H. with support from all co-authors.

564 All authors reviewed and approved the manuscript. 
FIGURE LEGENDS

Figure 1. Supplemented CONSORT diagram of patient disposition.

Figure 2. Principal efficacy outcomes per treatment.

Figure 3. Overall survival according to phosphorylated mTOR stratified by treatment.

(A) Kaplan-Meier curves shown represent patients separated by the phosphorylation status of mTOR $^{\text {Ser2448 }}$ (Pos, positive; Neg, negative) stratified for the two treatment arms CCl-

Figure 4. Multidimensional analysis of $m$-TOR associated markers.

579 The associations among markers in the mTOR pathway are illustrated by "The network representation" based on Spearman correlations between scores (A). (B) The glioblastoma subgroups based on mTOR pathway markers are visualized in a heatmap of the score table obtained after reconstruction using Non-linear Iterative Partial Least Squares (NIPALS). The rows were ordered by the first axis of the PCA. The columns are ordered by the consensus

584 classification ( $k=2$; clusters 1 , blue; cluster 2, red) and are annotated for absence or 585 presence of mutated $\mathrm{IDH} 1^{\mathrm{R} 132 \mathrm{H}}$ (positive, red; negative, grey; unknown; white), and the EGFR status (amplified dark green, non-amplified, green; unknown, white). The association between OS and consensus classification for two groups $(\mathrm{k}=2)$ (cluster 1, blue; cluster 2, red) is illustrated by Kaplan-Meier representation for patients randomized to $\mathrm{CCl}-779$ (C) and TMZ (D). The p-value is given for each KM. The patients (E) and m-TOR-associated markers (F) were projected onto the two first components of the principal component analysis (PCA). Inertia ellipses and stars visualize the separation of the patients into the two groups obtained from consensus clustering (cluster 1, blue; cluster 2, red) (E). 
Table Baseline characteristics

\begin{tabular}{|c|c|c|c|}
\hline & $\begin{array}{c}\text { TMZ } \\
(N=55)\end{array}$ & $\begin{array}{l}\text { Temsirolimus } \\
\qquad(\mathrm{N}=56)\end{array}$ & $\begin{array}{c}\text { Total } \\
(\mathrm{N}=111)\end{array}$ \\
\hline & $\mathbf{N}(\%)$ & $\mathbf{N}(\%)$ & N (\%) \\
\hline \multicolumn{4}{|l|}{ Age } \\
\hline median & 57.7 & 54.9 & 55.7 \\
\hline range & $24.4-76.0$ & $28.2-74.7$ & $24.4-76.0$ \\
\hline \multicolumn{4}{|l|}{ Sex } \\
\hline male & $36(65.5)$ & $35(62.5)$ & $71(64.0)$ \\
\hline female & $19(34.5)$ & $21(37.5)$ & $40(36.0)$ \\
\hline \multicolumn{4}{|l|}{$\begin{array}{l}\text { Extent of } \\
\text { resection }\end{array}$} \\
\hline $\begin{array}{l}\text { open } \\
\text { biopsy }\end{array}$ & $1(1.8)$ & $3(5.4)$ & $4(3.6)$ \\
\hline resection & $54(98.2)$ & $53(94.6)$ & $107(96.4)$ \\
\hline \multicolumn{4}{|l|}{ Corticosteroids } \\
\hline no & $37(67.3)$ & $40(71.4)$ & $77(69.4)$ \\
\hline yes & $18(32.7)$ & $16(28.6)$ & $33(29.7)$ \\
\hline \multicolumn{4}{|l|}{ WHO PS (0-4) } \\
\hline 0 & $40(72.7)$ & $32(57.1)$ & $72(64.9)$ \\
\hline 1 & $14(25.5)$ & $20(35.7)$ & $34(30.6)$ \\
\hline 2 & $1(1.8)$ & $4(7.1)$ & $5(4.5)$ \\
\hline
\end{tabular}

Abbreviations: TMZ, temozolomide; WHO PS, World Health Organization

Performance Status 


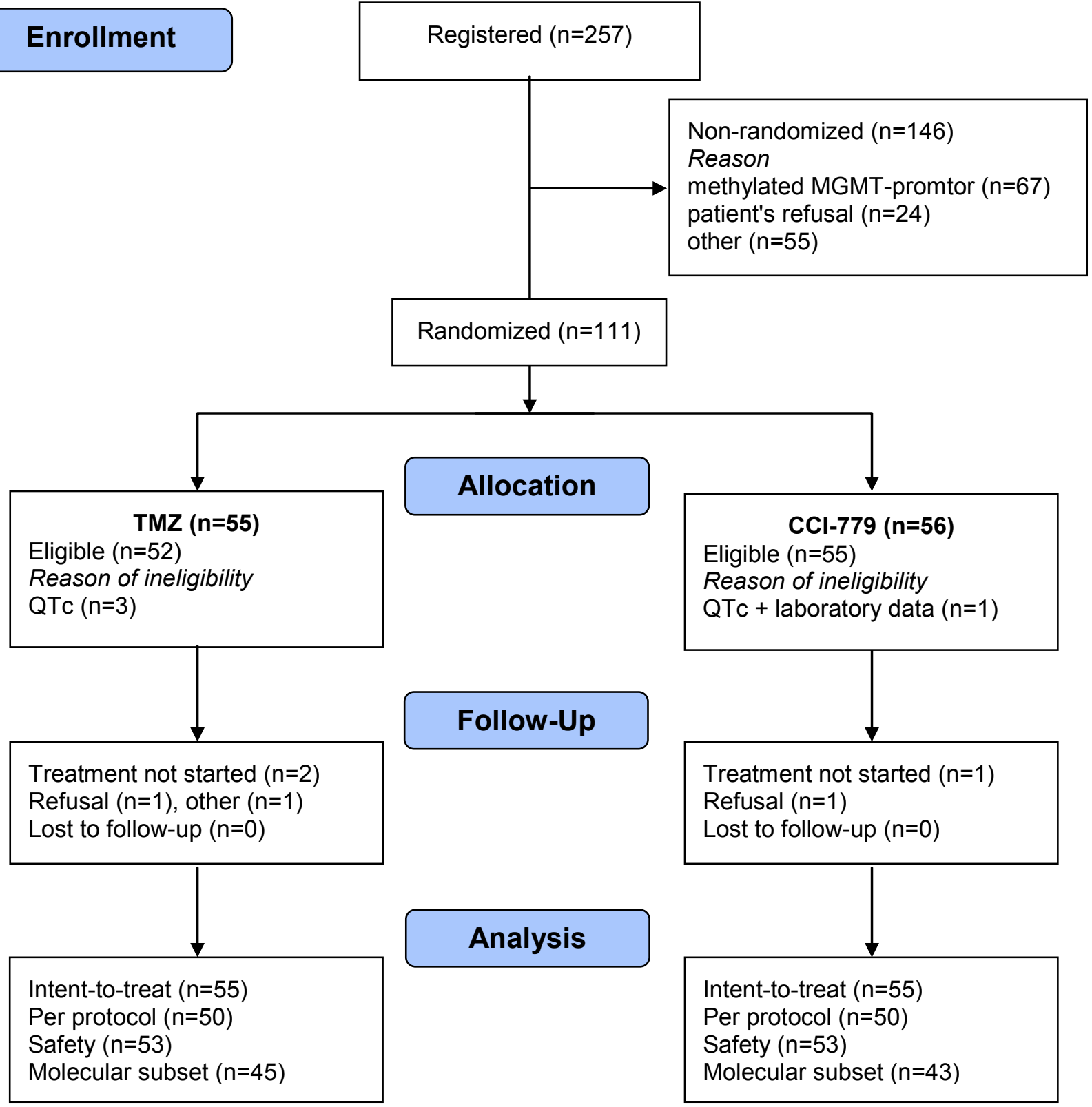


A

Overall Survival

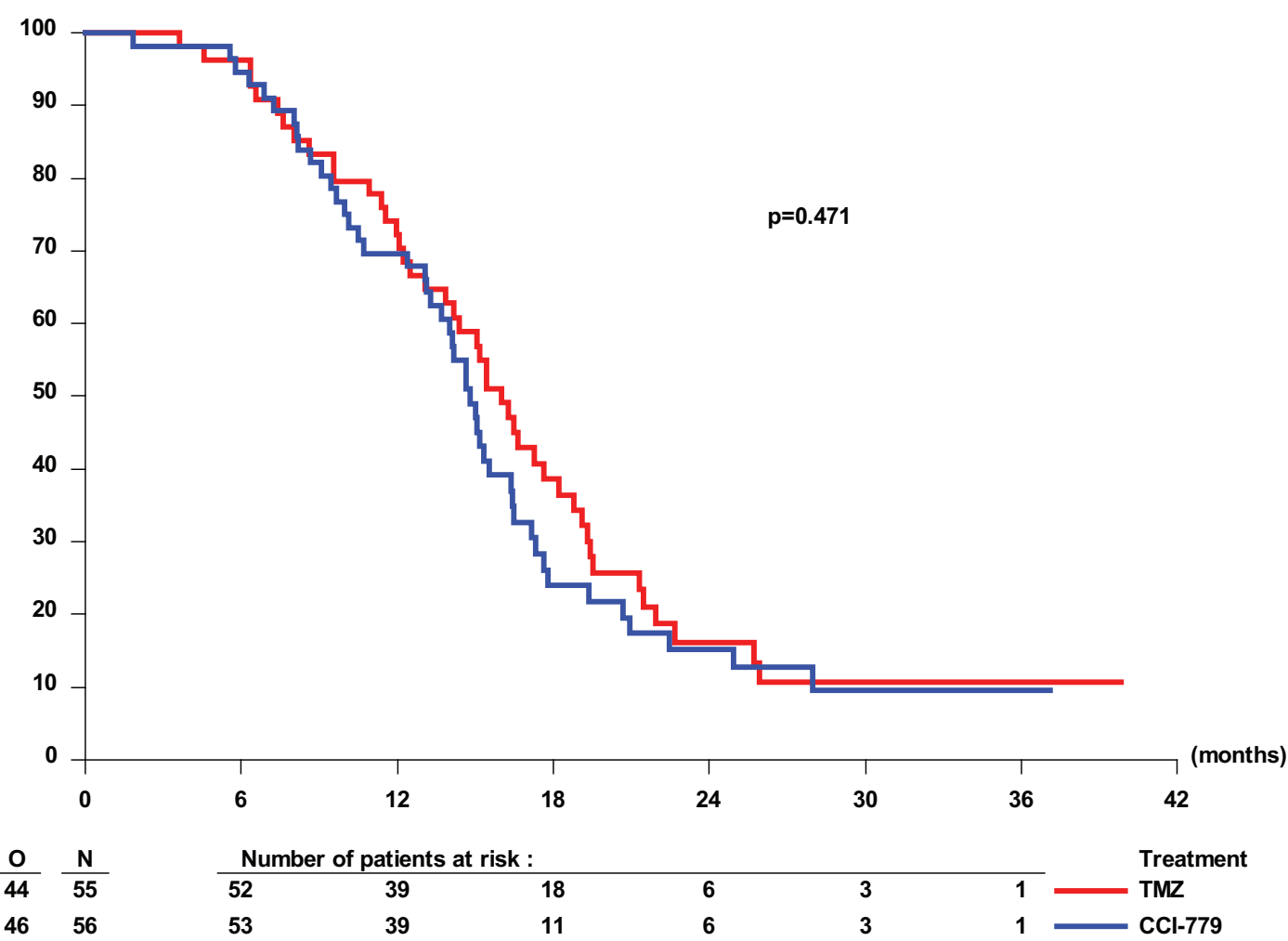

\begin{tabular}{|c|c|c|c|c|c|c|}
\hline \multicolumn{7}{|c|}{ Survival Time } \\
\hline Treatment & $\begin{array}{l}\text { Patients } \\
\text { (N) }\end{array}$ & $\begin{array}{l}\text { Observed } \\
\text { Events } \\
(0)\end{array}$ & $\begin{array}{l}\text { Hazard Ratio } \\
(95 \% \mathrm{Cl})\end{array}$ & $\begin{array}{c}\begin{array}{c}\text { P-Value } \\
\text { (Log-Rank) }\end{array} \\
\text { (Log }\end{array}$ & $\begin{array}{l}\text { Median (95\% Cl) } \\
\text { (Months) }\end{array}$ & $\begin{array}{l}\% \text { at } 1 \text { Year } \\
(95 \% \mathrm{Cl})\end{array}$ \\
\hline TMZ & 55 & 44 & 1.00 & 0.4708 & $16.03(13.83,18.20)$ & $72.22(58.22,82.22)$ \\
\hline $\mathrm{CCl}-779$ & 56 & 46 & $1.16(0.77,1.76)$ & & $14.78(13.27,16.39)$ & $69.64(55.79,79.91)$ \\
\hline
\end{tabular}

Downloaded from clincancerres.aacrjournals.org on May 19, 2016. (@ 2016 American Association for Cancer Research. 
Figure 2B

B

\section{Progression Free Survival}

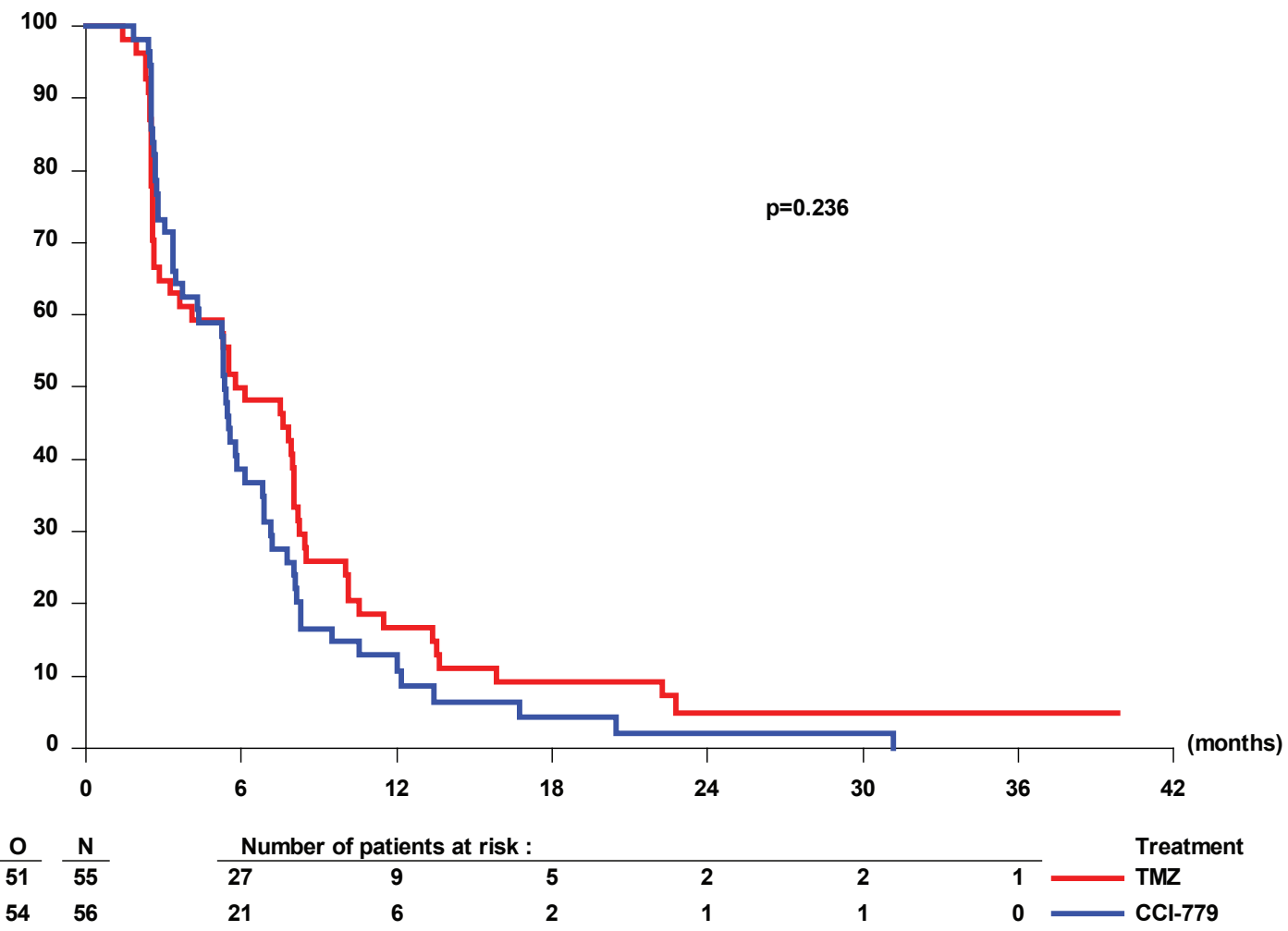

\begin{tabular}{|c|c|c|c|c|c|c|}
\hline Treatment & $\begin{array}{l}\text { Patients } \\
(\mathrm{N})\end{array}$ & $\begin{array}{l}\text { Observed } \\
\text { Events } \\
\text { (0) }\end{array}$ & $\begin{array}{c}\text { Hazard Ratio } \\
(95 \% \mathrm{Cl})\end{array}$ & $\begin{array}{c}\text { P-Value } \\
\text { (Log-Rank) }\end{array}$ & $\begin{array}{l}\text { Median }(95 \% \mathrm{Cl}) \\
\text { (Months) }\end{array}$ & $\begin{array}{c}\% \text { at } 0.5 \text { Year(s) } \\
(95 \% \mathrm{Cl})\end{array}$ \\
\hline TMZ & 55 & 51 & 1.00 & 0.2358 & $5.95(3.25,8.02)$ & $50.00(36.12,62.39)$ \\
\hline CCl-779 & 56 & 54 & $1.26(0.86,1.86)$ & & $5.36(3.71,6.14)$ & $38.67(25.96,51.20)$ \\
\hline
\end{tabular}




\section{Overall Survival}

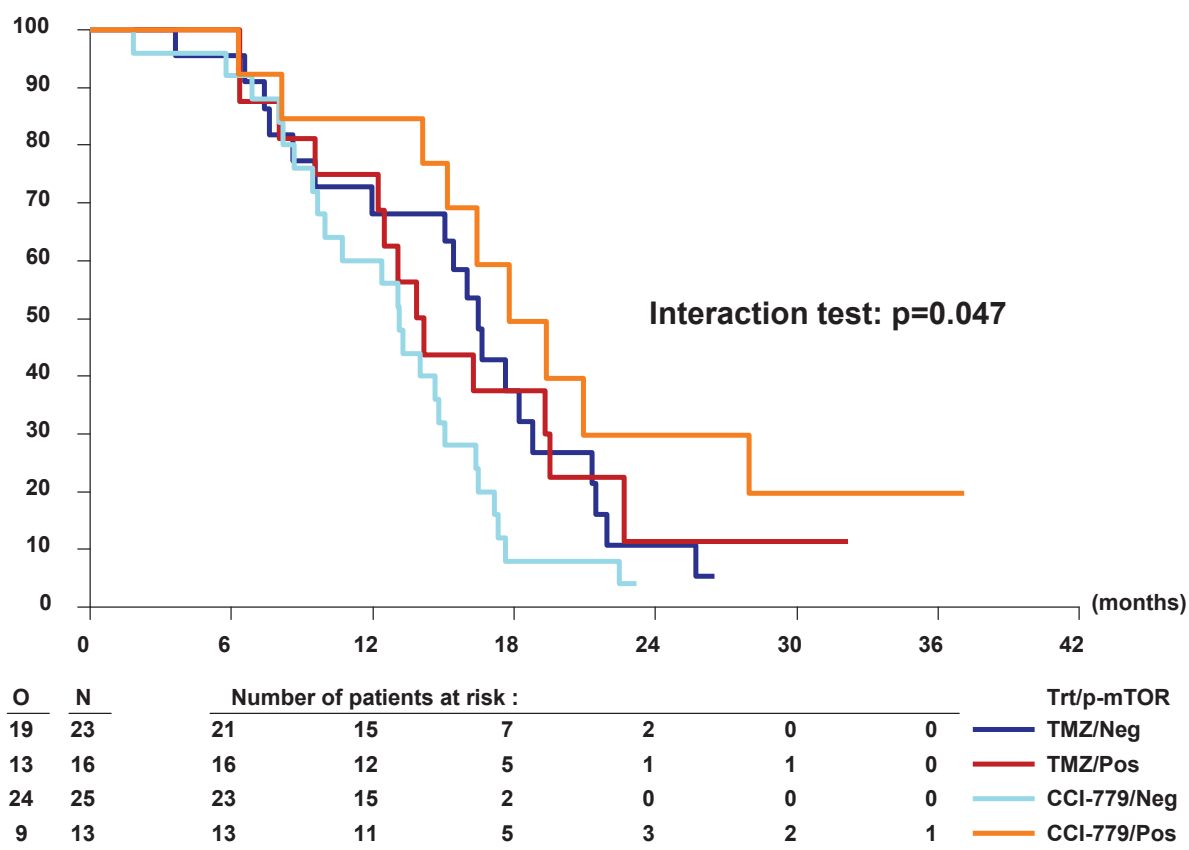

\begin{tabular}{|c|c|c|c|c|c|c|}
\hline \multicolumn{3}{|c|}{ Survival Time } & \multicolumn{2}{|c|}{ Non-parametric } & \multicolumn{2}{|c|}{ Cox model } \\
\hline treatment/p-mtor & $\begin{array}{l}\text { Patients } \\
\text { (N) }\end{array}$ & $\begin{array}{l}\text { Observed } \\
\text { Events } \\
\text { (0) }\end{array}$ & $\begin{array}{l}\text { Median }(95 \% \mathrm{Cl}) \\
\text { (Months) }\end{array}$ & $\begin{array}{c}\% \text { at } 2 \text { Year(s) } \\
(95 \% \mathrm{Cl})\end{array}$ & $\begin{array}{l}\text { Hazard Ratio } \\
(95 \% \mathrm{Cl})\end{array}$ & $\begin{array}{l}\text { P-Value } \\
\text { (Score test) }\end{array}$ \\
\hline TMZ/p-mTOR Neg & 23 & 19 & $16.46(9.53,18.79)$ & $10.7(1.8,28.7)$ & 1.00 & $0.042(\mathrm{df}=3)$ \\
\hline TMZ/p-mTOR Pos & 16 & 13 & $14.01(9.56,19.55)$ & $11.3(0.9,36.4)$ & $0.99(0.49,2.01)$ & \\
\hline CCI-779/p-mTOR Neg & 25 & 24 & $13.11(9.66,15.08)$ & $4.0(0.3,17.0)$ & $1.71(0.93,3.14)$ & \\
\hline CCI-779/p-mTOR Pos & 13 & 9 & $17.77(14.09,27.99)$ & $29.7(7.4,56.8)$ & $0.59(0.26,1.32)$ & \\
\hline & & & & & Log-rank test: & $p$-value $=0.041$ \\
\hline
\end{tabular}

B
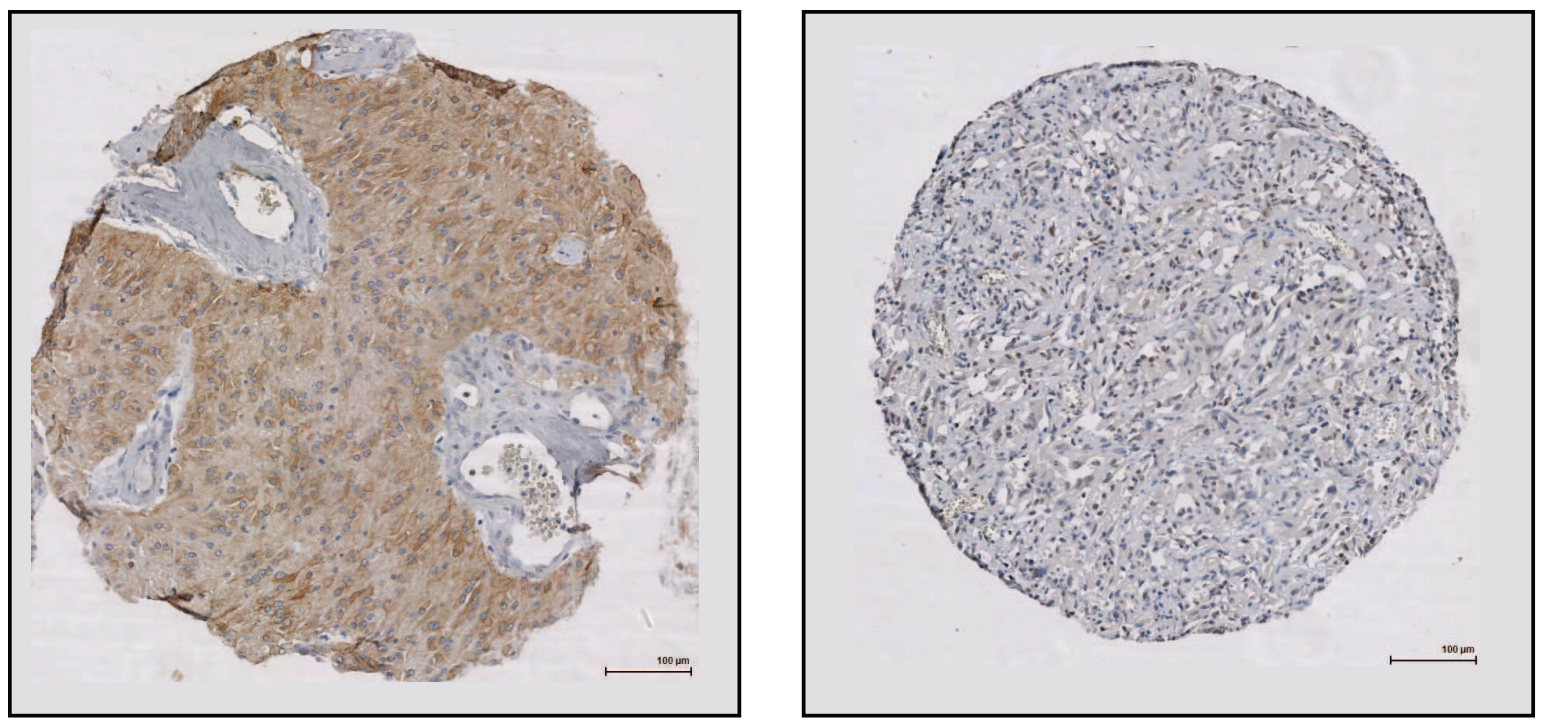
A Marker Correlations (Spearman correlation)

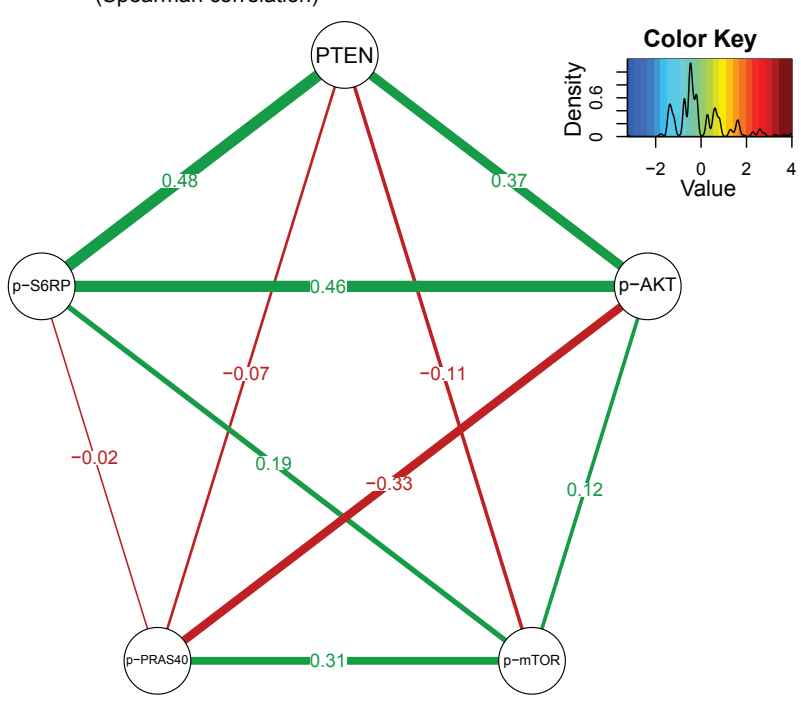

C Overall Survival (CCI-779)

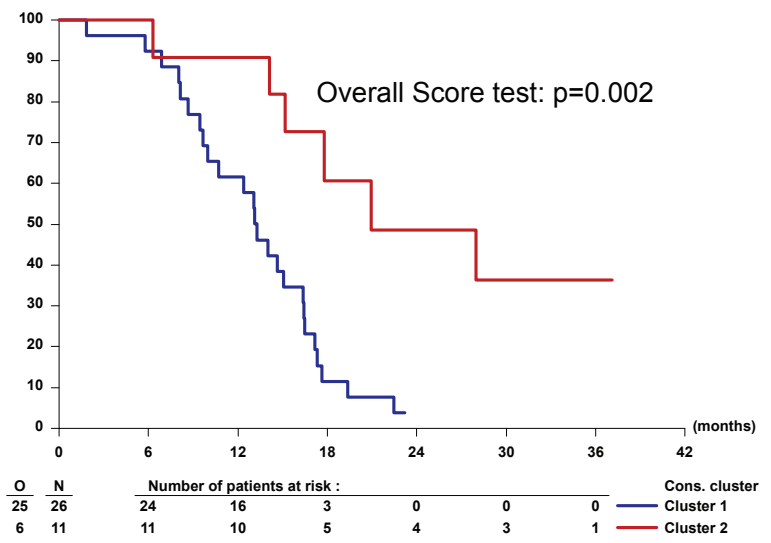

E

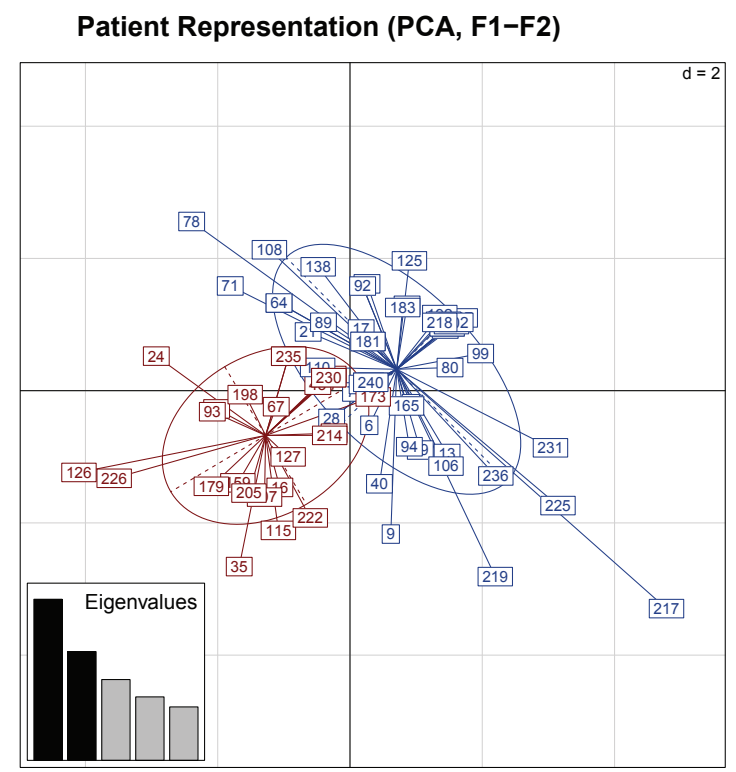

B

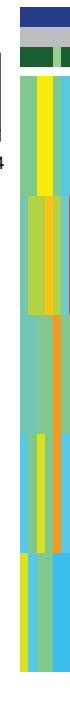

Consensus Clustering ( $k=2)$

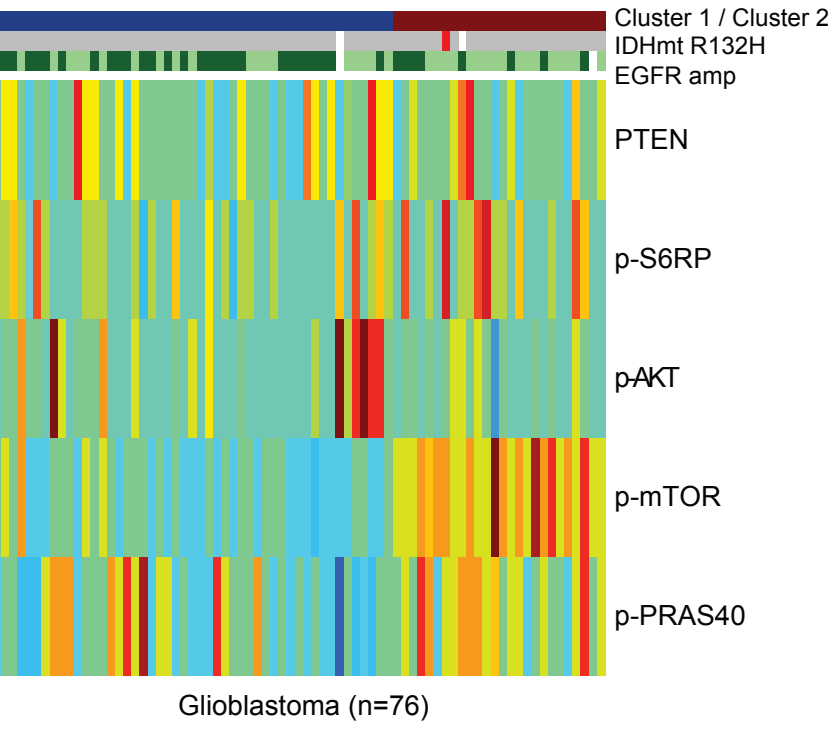

D Overall Survival (TMZ)

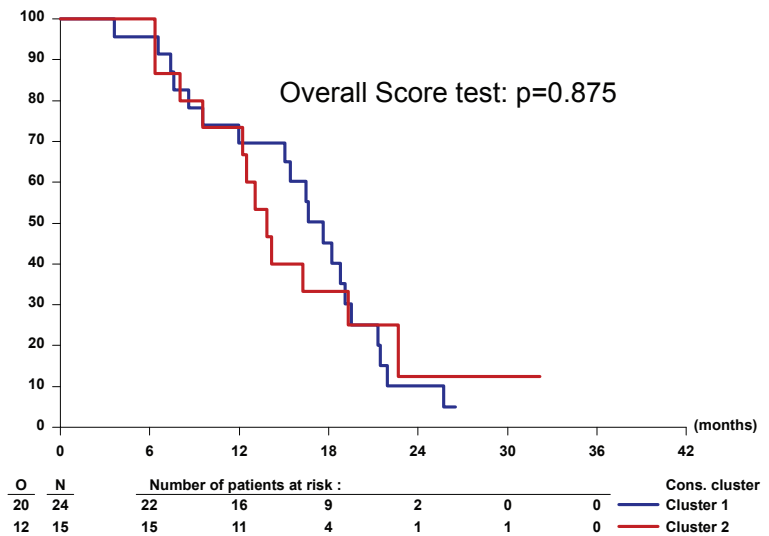

$\mathbf{F}$

Variable Representation (PCA, F1-F2)

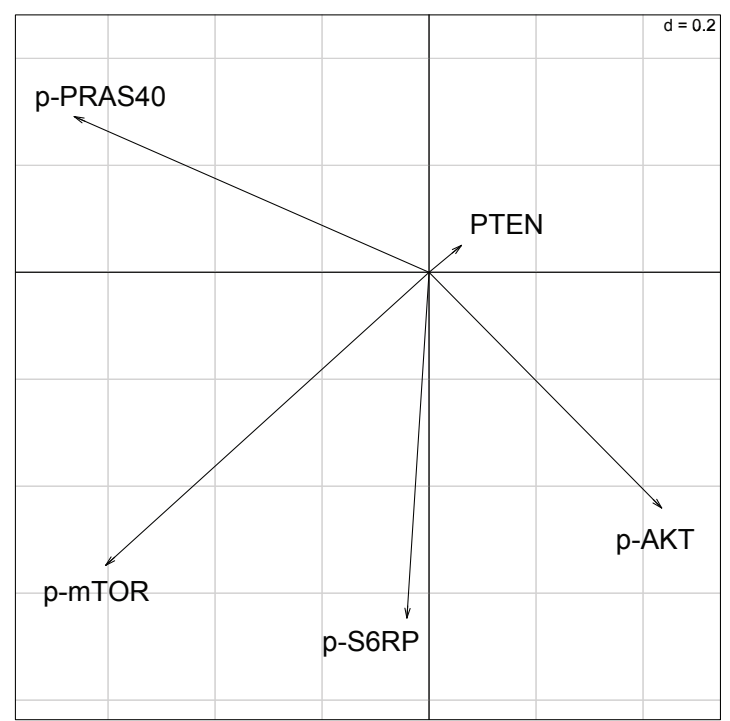

Downloaded from clincancerres.aacrjournals.org on May 19, 2016. (C 2016 American Association for Cancer Research. 
AACR

\section{Clinical Cancer Research}

Phase II study of radiotherapy and temsirolimus versus radiochemotherapy with temozolomide in patients with newly diagnosed glioblastoma without MGMT promoter hypermethylation (EORTC 26082)

Wolfgang Wick, Thierry Gorlia, Pierre Bady, et al.

Clin Cancer Res Published OnlineFirst May 3, 2016.

Updated version Access the most recent version of this article at: doi:10.1158/1078-0432.CCR-15-3153

Supplementary Access the most recent supplemental material at:

Material http://clincancerres.aacrjournals.org/content/suppl/2016/05/03/1078-0432.CCR-15-3153.DC1.html

Author Author manuscripts have been peer reviewed and accepted for publication but have not yet been Manuscript edited.

\section{E-mail alerts Sign up to receive free email-alerts related to this article or journal.}

Reprints and To order reprints of this article or to subscribe to the journal, contact the AACR Publications Subscriptions Department at pubs@aacr.org.

Permissions To request permission to re-use all or part of this article, contact the AACR Publications Department at permissions@aacr.org. 